\title{
Shape-Controlled Synthesis of Au Nanostructures Using EDTA Tetrasodium Salt and Their Photothermal Therapy Applications
}

\author{
Youngjin Jang ${ }^{1}$, Nohyun Lee ${ }^{2}$, Jeong Hyun Kim ${ }^{3}$, Yong Il Park ${ }^{4, *(D)}$ and Yuanzhe Piao ${ }^{5, *}$ \\ 1 Schulich Faculty of Chemistry, Technion-Israel Institute of Technology, Haifa 3200003, Israel; \\ youngjin@technion.ac.il \\ 2 School of Advanced Materials Engineering, Kookmin University, Seoul 02707, Korea; \\ nohyunlee@kookmin.ac.kr \\ 3 Center for Nanoparticle Research, Institute for Basic Science, and School of Chemical and Biological \\ Engineering, Seoul National University, Seoul 151-742, Korea; jhkim113@snu.ac.kr \\ 4 School of Chemical Engineering, Chonnam National University, Gwangju 61186, Korea \\ 5 Graduate School of Convergence Science and Technology \& Advanced Institutes of Convergence \\ Technology, Seoul National University, Suwon 16229, Korea \\ * Correspondence: ypark@jnu.ac.kr (Y.I.P.); parkat9@snu.ac.kr (Y.P.); \\ Tel.: +82-62-530-1886 (Y.I.P.); +82-31-888-9141 (Y.P.)
}

Received: 27 March 2018; Accepted: 16 April 2018; Published: 18 April 2018

\begin{abstract}
Tuning the optical properties of Au nanostructures is of paramount importance for scientific interest and has a wide variety of applications. Since the surface plasmon resonance properties of Au nanostructures can be readily adjusted by changing their shape, many approaches for preparing Au nanostructures with various shapes have been reported to date. However, complicated steps or the addition of several reagents would be required to achieve shape control of Au nanostructures. The present work describes a facile and effective shape-controlled synthesis of Au nanostructures and their photothermal therapy applications. The preparation procedure involved the reaction of $\mathrm{HAuCl}_{4}$ and ethylenediaminetetraacetic acid (EDTA) tetrasodium salt, which acted as a reducing agent and ligand, at room temperature without the need for any toxic reagent or additives. The morphology control from spheres to branched forms and nanowire networks was easily achieved by varying the EDTA concentration. Detailed investigations revealed that the four carboxylic groups of the EDTA tetrasodium salt are essential for effective growth and stabilization. The produced Au nanowire networks exhibited a broad absorption band in the near-infrared (NIR) region, thereby showing efficient cancer therapeutic performance by inducing the selective photothermal destruction of cancerous glioblastoma cells (U87MG) under NIR irradiation.
\end{abstract}

Keywords: gold; nanostructure; EDTA tetrasodium salt; photothermal therapy

\section{Introduction}

To date, metal nanostructures have attracted a great deal of attention because of their intriguing electronic, optical, and catalytic properties [1-7]. In the past few decades, Au nanostructures of various shapes, including nanospheres [8-10], nanorods [11-19], nanowires [20-26], polyhedrons [27-32], nanoplates [33-35], nanoshells [36-38], and branched forms [39-49], have been extensively explored because of their shape-dependent surface plasmon resonance properties [50-53]. The fascinating surface plasmon resonance properties of Au nanostructures enable their effective implementation in a wide variety of biomedical applications, such as cancer therapy, bio-imaging, biological sensing, and diagnostics [54-58]. Biological targets (e.g., protein and DNA) are recognized as changes 
in the absorption of the functionalized Au nanostructures and an efficient bio-imaging using Au nanostructures is achieved by their distinctive interactions with light. Photothermal therapy is one of the major therapeutic methods that requires near-infrared (NIR) light, which shows maximum penetration depths in tissues and has a low toxicity for normal cells, so that cancer cells can be killed by heat generation [56,59-70]. To obtain Au nanostructures exhibiting optical properties active in the NIR region, intricate methods including multiple steps, many reagents, or long reaction times have been applied. For example, a seed-mediated growth approach has been widely used to produce anisotropic Au nanostructures, such as nanorods, which require steps for the formation of Au seeds and their growth. In addition, a method using two (or more) appropriate capping reagents with different binding affinities has been developed to obtain kinetic control of the growth rates on various crystal planes, resulting in the formation of non-spherical Au nanostructures. Therefore, the development of Au nanostructure preparation that yields NIR absorption is of prime importance for the successful extension to practical applications.

Recently, it was reported that ethylenediaminetetraacetic acid (EDTA), a well-known metal chelating ligand, can act as a reducing agent [71-73]. However, to the best of our knowledge, the morphology control of $\mathrm{Au}$ nanostructures by applying EDTA agents has not been attempted. Therefore, this is pioneering work on the preparation of Au nanocrystals exhibiting NIR activities using EDTA agents at room temperature.

Herein we present a facile and effective shape-controlled synthesis of colloidal Au nanostructures at room temperature and their effective performance for photothermal therapy. This simple procedure was achieved by reacting $\mathrm{HAuCl}_{4}$ and EDTA tetrasodium salt, exhibiting a dual function as a reductant and a stabilizing agent, without any toxic compounds such as cetyltriethylammonium bromide or additional agents (e.g., superhydride). The morphology of the Au nanostructures was readily controlled by adjusting the molar ratio of the EDTA tetrasodium salt to the $\mathrm{HAuCl}_{4}$ precursor. Reducing the concentration of the EDTA tetrasodium salt led to the formation of Au nanowire networks that are active in the NIR regime. Control experiments using several kinds of EDTA agents revealed that the four deprotonated carboxylic groups of EDTA tetrasodium salt play a key role as stabilizing agents and in effective growth control. The Au nanowire networks showed an effective and selective photothermal therapeutic effect on cancerous glioblastoma cells (U87MG) under NIR irradiation at $980 \mathrm{~nm}$.

\section{Materials and Methods}

\subsection{Materials}

EDTA, EDTA disodium salt, and EDTA tetrasodium salt were purchased from Samchun Chemicals (Seoul, Korea). Tetrachloroaurate trihydrate $\left(\mathrm{HAuCl}_{4} \cdot 3 \mathrm{H}_{2} \mathrm{O}\right)$ was purchased from Strem Chemicals, Inc. (Newburyport, MA, USA). Methoxy poly(ethylene glycol)sulfhydryl (mPEG-SH, $\left.\mathrm{M}_{\mathrm{w}}=5000\right)$ was purchased from SunBio Corp. (Anyang, Korea). Water deionized by a Nano Pure System (Barnstead, Thermo Fisher Scientific, Waltham, MA, USA) was used. The chemicals used for the preparation of the solutions were purchased at the highest grade possible, and used without further purification.

\subsection{Shape-Controlled Synthesis of Au Nanostructures}

To synthesize Au nanowires with a network structure, $15 \mathrm{mg}$ of EDTA tetrasodium salt was injected into $7 \mathrm{~mL}$ of deionized water at room temperature, and the mixture solution was stirred for a few minutes to ensure complete dissolution of the salt. Further, $0.1 \mathrm{~mL}$ of $0.1 \mathrm{M} \mathrm{HAuCl}_{4}$ was added to the aqueous solution containing the EDTA tetrasodium salt at room temperature, and the resulting solution was vigorously stirred for $1 \mathrm{~h}$. After the reaction, the mixture was washed with water by centrifugation at 14,000 rpm for $10 \mathrm{~min}$. To synthesize the branched Au nanoparticles, the molar ratio of $\mathrm{HAuCl}_{4}$ to EDTA tetrasodium salt was changed to 1:6, and other conditions were kept constant. To synthesize the spherical Au nanoparticles, the molar ratio of $\mathrm{HAuCl}_{4}$ to EDTA tetrasodium salt was increased to $1: 8$. 
To stabilize the Au nanowire networks, an mPEG-SH aqueous solution prepared by dissolving 40 $\mathrm{mg}$ of $\mathrm{mPEG}-\mathrm{SH}$ in $2 \mathrm{~mL}$ of deionized water was injected into the mixture solution and further stirred for $30 \mathrm{~min}$. The resulting solution was washed with water by centrifugation at 14,000 rpm for $15 \mathrm{~min}$.

\subsection{In Vitro Cytotoxicity against U87MG Cells}

U87MG human glioblastoma cells were grown as monolayer cultures in a 100-mm dish and subcultured 3 times a week at $37^{\circ} \mathrm{C}$ in an atmosphere of $5 \% \mathrm{CO}_{2}$ and $100 \%$ relative humidity. For the in vitro cytotoxicity assay, cells at a logarithmic growth phase were detached and plated $(0.2 \mathrm{~mL}$ per well) in 96-well flat-bottomed microplates at a density of 10,000 cells per well, which were then left for 1-2 days at $37^{\circ} \mathrm{C}$ to resume exponential growth. After washing the cells with phosphate buffered saline (PBS), $0.1 \mathrm{~mL}$ of the culture medium, with various concentrations of Au nanowire networks coated with mPEG-SH ligand, was added to the wells in quintuplicate. For the control wells, the same volume of culture medium was included in each experiment. Following $24 \mathrm{~h}$ of continuous exposure to the $\mathrm{Au}$ nanowire networks under $5 \% \mathrm{CO}_{2}$ atmosphere at $37{ }^{\circ} \mathrm{C}$, cell survival was assessed using the (3-(4,5-dimethylthiazol-2-yl)-2,5-diphenyltetrazolium bromide (MTT) cell proliferation assay.

\subsection{In Vitro Photothermal Therapy}

The U87MG human glioblastoma cells were plated in a confocal dish and allowed to grow on the coverslip. Additionally, $150 \mu \mathrm{g} \mathrm{Au} / \mathrm{mL}$ of the Au nanowire networks coated with mPEG-SH ligand were incubated with the cells for $24 \mathrm{~h}$. The unbound Au nanowire networks were rinsed with the PBS buffer, and the cells were immersed in the culture medium.

Subsequently, a 980-nm continuous wave (CW) diode laser was used for irradiation and was focused to a 1-mm-diameter spot on the sample (power density: $38.2 \mathrm{~W} / \mathrm{cm}^{2}$ ). The cells were irradiated for $10 \mathrm{~min}$. The control cells without the Au nanowire networks with laser irradiation were also tested. Subsequently, the cells were stained with a few drops of $0.4 \%$ trypan blue to test viability. The dead cells were stained blue, while the live cells remained clear. After staining, the cells were rinsed with the PBS buffer and immersed in the culture medium for bright-field imaging.

\subsection{Characterization}

Transmission electron microscopy (TEM) and high-resolution TEM (HR-TEM) images were acquired using a JEOL EM-2010 microscope (JEOL, Tokyo, Japan) at an accelerating voltage of $200 \mathrm{kV}$. The powder X-ray diffraction (XRD) pattern was obtained by a Rigaku D/Max-3C diffractometer ( $\mathrm{Cu} \mathrm{K} \alpha$ radiation, $\lambda=0.15418 \mathrm{~nm}$, Rigaku Co. Ltd., Tokyo, Japan). The UV-Vis absorption spectra were acquired by a Jasco V-570-type spectrophotometer (Jasco SLM-468, Tokyo, Japan). Elemental analysis was performed by inductively coupled plasma-atomic emission spectroscopy (ICP-AES) using an ICPS-7500 spectrometer (Shimadzu, Kyoto, Japan). The MTT cell proliferation assay was performed by an ELx808TM absorbance microplate reader (Biotek Instruments Inc., Winooski, VT, USA).

\section{Results and Discussion}

In general, colloidal synthesis of Au nanostructures requires reductants and capping agents. In the current procedure, the $\mathrm{Au}$ nanostructures were readily synthesized by reacting $\mathrm{HAuCl}_{4}$ and EDTA tetrasodium salt in an aqueous solution at room temperature. The EDTA tetrasodium salt played a dual role as a reducing agent and as a ligand, thus allowing for simple synthesis without any additives. After the reaction, the products were washed with water to remove any byproducts and unreacted reagents. More details are provided in the experimental section.

Figure 1a shows a representative TEM image of the Au nanostructures prepared using a 1:8 molar ratio of $\mathrm{HAuCl}_{4}$ to EDTA tetrasodium salt. The image presents the formation of spherical Au nanocrystals with an average diameter of $11 \mathrm{~nm}$. A HR-TEM image is shown in the inset of Figure 1a, indicating the polycrystallinity of the Au nanocrystals with pronounced lattice fringes of $0.235 \mathrm{~nm}$, corresponding to the (111) planes of a face-centered-cubic (fcc) Au crystal structure. Decreasing 
the molar ratio of $\mathrm{HAuCl}_{4}$ to EDTA tetrasodium salt induced shape control, resulting in branched forms (see Figure 1b) at 1:6 and nanowire networks (see Figure 1c) at 1:4. When the molar ratio was below 1:3, severely aggregated Au particles were observed because of the insufficient capping agent. Based on these observations, the formation of the Au nanostructures is summarized in Scheme 1, illustrating that the morphology of the Au nanostructures is easily controlled by adjusting the EDTA tetrasodium salt concentration. High concentrations of EDTA tetrasodium salt produced only spherical $\mathrm{Au}$ nanocrystals. Decreasing the molar ratio of $\mathrm{HAuCl}_{4}$ to EDTA tetrasodium salt resulted in the formation of non-spherical Au nanostructures, such as branched forms and nanowire networks.
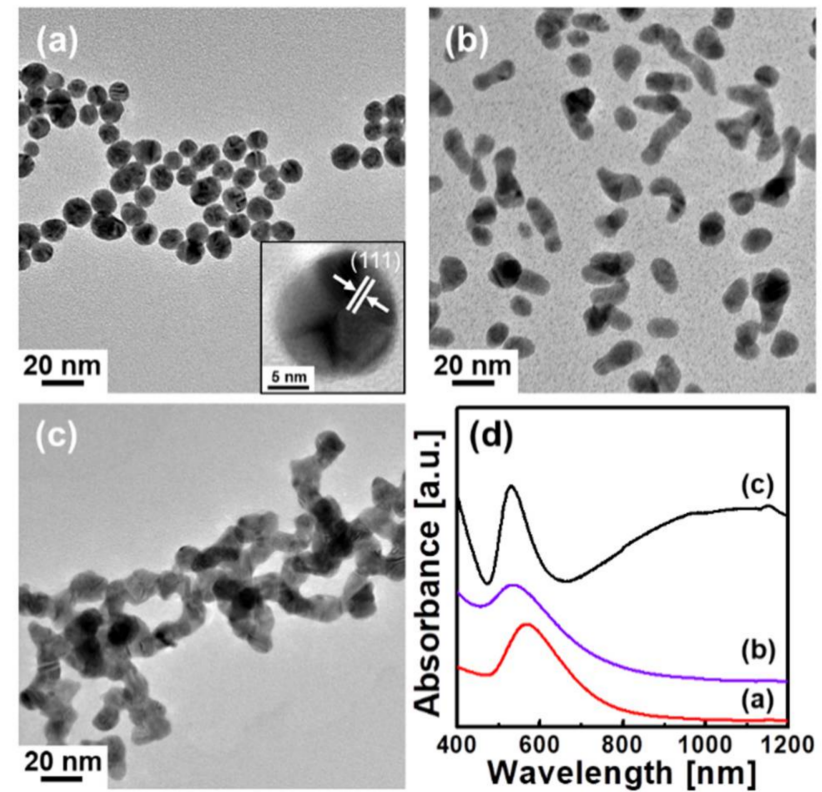

Figure 1. Transmission electron microscopy (TEM) images of Au nanostructures prepared using different molar ratios of $\mathrm{HAuCl}_{4}$ to ethylenediaminetetraacetic acid (EDTA) tetrasodium salt: (a) 1:8, the inset is the high-resolution TEM (HR-TEM) image of panel (a); (b) 1:6; (c) 1:4; (d) Absorption spectra of Au nanostructures in panels $(\mathbf{a}-\mathbf{c})$.

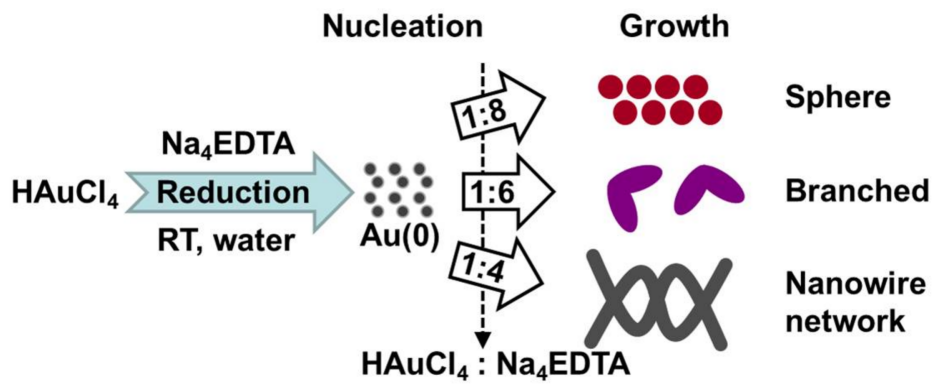

Scheme 1. Schematic illustration of morphology control by adjusting the molar ratio of $\mathrm{HAuCl}_{4}$ to EDTA tetrasodium salt.

The absorption spectra of Au nanostructures, with three kinds of morphologies, are presented in Figure $1 \mathrm{~d}$, clearly displaying the shape-dependent surface plasmon resonance behaviors. Spherical Au nanocrystals (see red curve (a) in Figure 1d) exhibit one absorption peak at $570 \mathrm{~nm}$, resulting from the transverse mode, while the transverse band becomes broader in the branched Au nanostructures (see purple curve (b) in Figure 1d). The most intriguing activity was observed when using a 1:4 molar ratio of $\mathrm{HAuCl}_{4}$ to EDTA tetrasodium salt (see black curve (c) in Figure 1d). Two distinct optical behaviors were identified in the absorption spectrum of the Au nanowire networks. The peak at 530 
$\mathrm{nm}$ is attributed to transverse surface plasmon resonance (TSPR), and a broad absorption band over the NIR spectra regime was observed, owing to the longitudinal surface plasmon resonance (LSPR).

The Au nanowire networks showing absorption in the NIR regime were further investigated, as described below. The low-magnification TEM image of the Au nanowire networks in Figure 2a reveals that the wires have considerable lengths of a few micrometers. HR-TEM images of the Au nanowire networks are displayed in Figure 2b,c, indicating the dominant (111) lattice planes, in agreement with the fast Fourier transform (FFT) image shown in the inset. Moreover, these images provide insight into the crystallinity of the Au nanowire networks and their growth characteristics, acquired by the coalescence of $\mathrm{Au}$ particles and subsequent deposition of $\mathrm{Au}$ atoms, as suggested in previous studies [21,22,74].

The XRD pattern of the $\mathrm{Au}$ nanowire networks is presented in Figure $2 \mathrm{~d}$, showing that all characteristic peaks are indexed to the (111), (200), (220), (311) and (222) planes of the fcc Au crystal structure without any other phases, which also supports the TEM analysis.

When the solution containing the isolated Au nanowire networks was kept at room temperature for approximately one day, the color gradually changed from black to deep red, implying the transformation of the Au nanowire networks into spherical Au nanoparticles. The shape instability of nonspherical Au nanostructures has also been observed in previous works [21,22,42,43] and explained by the thermodynamic instability of the nonspheres [42,43]. To prevent the transformation of the Au nanowire networks, a stabilizing agent exhibiting stronger binding, the mPEG-SH ligand, was used. mPEG-SH stabilized the Au nanowire networks and remained intact without any color change over one month, as shown in Figure S1 in the Supplementary Materials. The absorption spectra and TEM image in Figure S1 also support that mPEG-SH coating stabilize Au nanowire networks without morphological change.
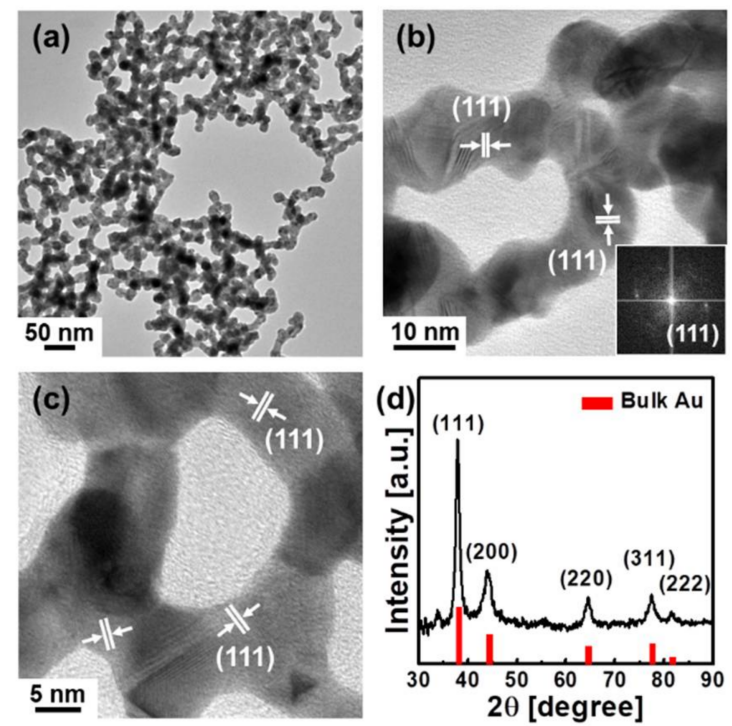

Figure 2. Characteristics of Au nanowire networks: (a,b) TEM images with different magnifications, the inset is the fast Fourier transform (FFT) image obtained from the panel (b); (c) HR-TEM images; (d) X-ray diffraction (XRD) pattern, red vertical lines indicate peak positions and relative intensities of bulk Au.

To monitor the temporal evolution of the Au nanowire networks during the reaction time of $1 \mathrm{~h}$, aliquots withdrawn at different reaction stages were analyzed, as shown in Figure 3 . As seen in the TEM images, the length and diameter of the wires gradually increased as the reaction time progressed, implying that the Au nanowire networks were formed by depositing the Au monomer at the joints between the assembled Au nanocrystals. The absorption spectra of aliquots taken at different reaction 
stages are also shown in Figure S2, indicating that only one broad feature was seen at the beginning stages (e.g., $15 \mathrm{~min}$ ). After $25 \mathrm{~min}$, two distinct peaks were clearly observed, due to the TSPR and LSPR modes. This evolution shows that Au nanowire networks formed in nearly $25 \mathrm{~min}$, in good agreement with the TEM analysis (see Figure 3f).
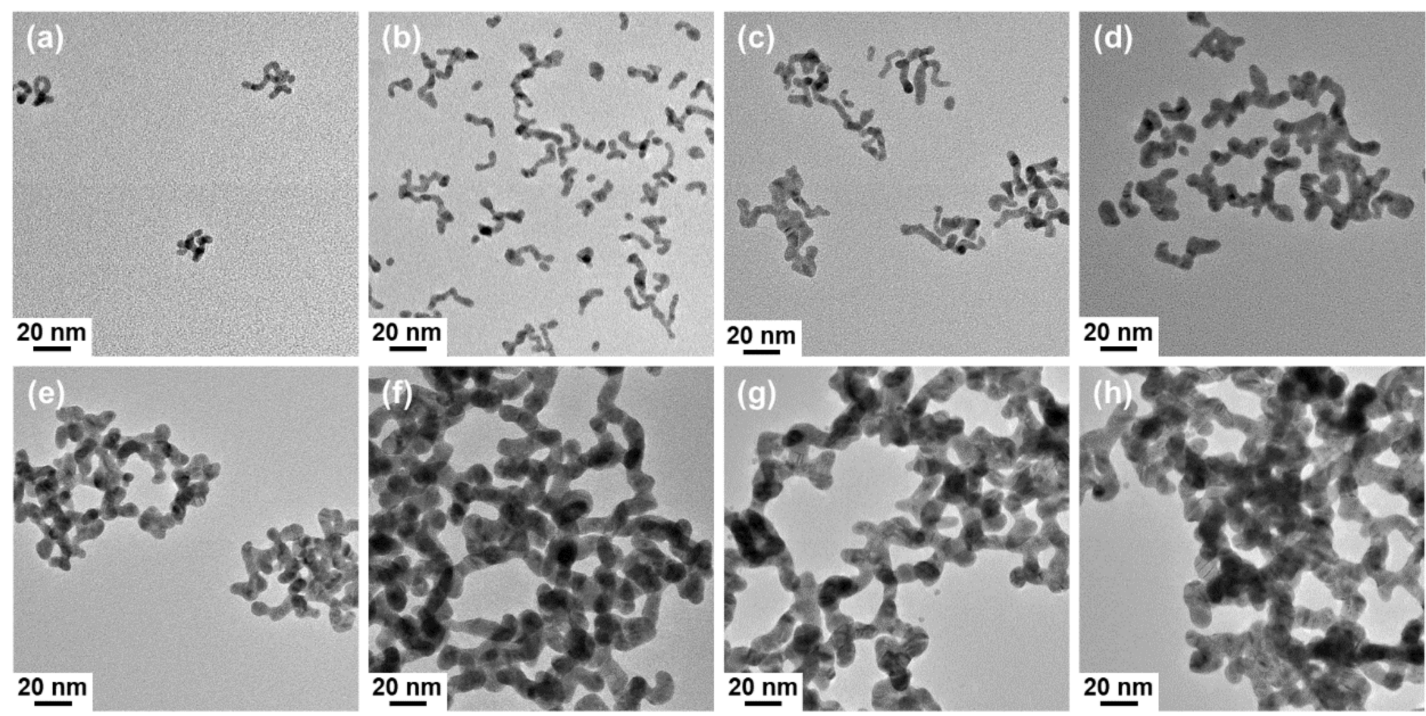

Figure 3. TEM images of the samples at different stages of the reaction: (a) $2 \mathrm{~min}$; (b) $5 \mathrm{~min}$; (c) $10 \mathrm{~min}$; (d) $15 \mathrm{~min}$; (e) $20 \mathrm{~min}$; (f) $25 \mathrm{~min}$; (g) $45 \mathrm{~min}$; (h) $60 \mathrm{~min}$.

Several kinds of control experiments were performed to understand the effects of synthetic conditions. Without the addition of the EDTA tetrasodium salt, no Au nanostructures were formed. This supports the fact that the four carboxylic groups of the EDTA tetrasodium salt reduce the $\mathrm{Au}^{3+}$ species, which is in agreement with previous works [71-73]. It is noteworthy that EDTA tetrasodium salt introduced strong basic conditions, thus eliminating the need for additional steps (see Table S1 in the Supplementary Materials), whereas adjusting the $\mathrm{pH}$ by adding a suitable base was necessary for the preparation of the Au nanostructures in previous studies [72,75,76].

In addition, the addition of other EDTA salts was attempted for the synthesis of Au nanostructures. Under similar conditions such as temperature and concentration, the use of EDTA and EDTA disodium salt led to the formation of micrometer-sized and submicrometer-sized Au aggregates, respectively, as shown in Figure S3, revealing that the four deprotonated carboxyl groups $\left(\mathrm{COO}^{-}\right)$of EDTA tetrasodium salt as a tetradentate group are essential for allowing effective growth on the nanoscale.

NIR absorption is crucial for many biomedical applications because biological tissues, blood, and water show low absorption in this wavelength range [77,78]. The cytotoxicity of the Au nanowire networks coated with mPEG-SH was evaluated to demonstrate their applicability as photothermal therapeutic agents. The MTT cell proliferation assay is presented in Figure S4, indicating that more than $80 \%$ of the U87MG cells survived up to $1.27 \mathrm{mM}(250 \mu \mathrm{g} / \mathrm{mL})$ of the Au concentration. A more detailed procedure is presented in the Experimental Section.

Figure 4 represents the images of the U87MG cells without and with the Au nanowire networks after the NIR laser irradiation at $980 \mathrm{~nm}$ for $10 \mathrm{~min}$, clearly revealing cell damage at the center of the laser beam for cells with an incubation of the Au nanowire networks, while the control cells remained intact. The dead cells were stained blue by $0.4 \%$ trypan blue. This observation clearly demonstrates the effectiveness of the Au nanowire networks in NIR photothermal therapy by selective killing of cancer cells, because of the local heating generated by their effective NIR absorption. Because of their relatively large size and irregular shape, the Au nanowire networks may not be suitable for animal study by systemic delivery. However, due to the good photothermal effect by NIR light, they can be 
used as a local heat generator to regulate cellular activity by attaching them to the cell membrane or biochip surface [79].
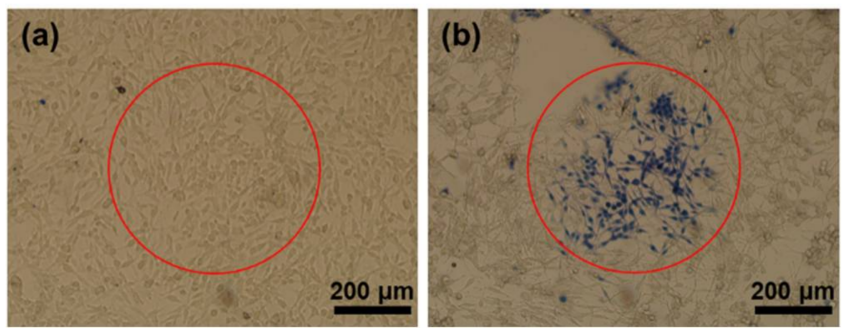

Figure 4. Optical microscope images of cancerous glioblastoma cells (U87MG) cells incubated (a) without; (b) with the Au nanowire networks, after irradiation for 10 min with a 980-nm near-infrared (NIR) CW diode laser and subsequent staining with $0.4 \%$ trypan blue.

\section{Conclusions}

In summary, our work presents a facile and effective shape-controlled synthesis of $\mathrm{Au}$ nanostructures and their photothermal therapeutic effect. The described procedure involves the simple mixing of $\mathrm{HAuCl}_{4}$ and EDTA tetrasodium salt in an aqueous solution at room temperature, without additional ligands or toxic reagents. Adjusting the molar ratios of $\mathrm{HAuCl}_{4}$ to EDTA tetrasodium salt enables effective morphology control of Au nanostructures from spheres to branched forms and nanowire networks. Detailed control experiments revealed that the four deprotonated carboxylic acids of the EDTA tetrasodium salt provided effective growth control and stabilization. The Au nanowire networks showed strong absorption in the NIR region and hence were suitable for photothermal therapy. Under NIR irradiation, the Au nanowire networks allowed for selective destruction of cancerous U87MG cells by local heating, generated by the NIR absorption. This work demonstrates the development of a simple synthetic route to NIR-active Au nanostructures, which can be extended to other applications including optical sensing and surface-enhanced Raman scattering.

Supplementary Materials: The following are available online at http:/ /www.mdpi.com/2079-4991/8/4/252/s1, Figure S1: (a) Photograph of mPEG-SH stabilized Au nanowire networks kept in ambient conditions for one month, showing good stability, (b) absorption spectra of as-synthesized Au nanowire networks (black curve) and mPEG-SH coated Au nanowire networks (red curve), and (c) TEM image of Au nanowire networks after mPEG-SH coating, Figure S2: Absorption spectra of Au nanostructures taken at different stages of the reaction, Figure S3: TEM images of Au aggregates generated by using (a) EDTA and (b) EDTA disodium salt, Figure S4: The cell viability of Au nanowire networks by MTT assay, Table S1: The $\mathrm{pH}$ values at different reaction conditions.

Acknowledgments: Y.P. was supported by the Center for Integrated Smart Sensors, funded by the Ministry of Science, ICT and Future Planning, Republic of Korea, as a Global Frontier Project (CISS-012M3A6A6054186). Y.I.P. was supported by the National Research Foundation of Korea (NRF) grant funded by the Korean government (Ministry of Science, ICT \& Future Planning) (No. 2016R1A4A1012224).

Author Contributions: Y.J., Y.I.P. and Y.P. conceived and designed the experiments; Y.J. and Y.P. performed the synthesis experiments; Y.I.P. performed the photothermal therapy experiments; N.L. performed the MTT assay experiments; J.H.K. executed the article editing; Y.J., Y.I.P. and Y.P. wrote the paper.

Conflicts of Interest: The authors declare no conflict of interest.

\section{References}

1. Schmid, G.; Corain, B. Nanoparticulated gold: Syntheses, structures, electronics, and reactivities. Eur. J. Inorg. Chem. 2003, 2003, 3081-3098. [CrossRef]

2. Daniel, M.C.; Astruc, D. Gold nanoparticles: Assembly, supramolecular chemistry, quantum-size-related properties, and applications toward biology, catalysis, and nanotechnology. Chem. Rev. 2004, 104, 293-346. [CrossRef] [PubMed] 
3. Eustis, S.; El-Sayed, M.A. Why gold nanoparticles are more precious than pretty gold: Noble metal surface plasmon resonance and its enhancement of the radiative and nonradiative properties of nanocrystals of different shapes. Chem. Soc. Rev. 2006, 35, 209-217. [CrossRef] [PubMed]

4. Hutchings, G.J.; Brust, M.; Schmidbaur, H. Gold-an introductory perspective. Chem. Soc. Rev. 2008, 37, 1759-1765. [CrossRef] [PubMed]

5. Grzelczak, M.; Perez-Juste, J.; Mulvaney, P.; Liz-Marzan, L.M. Shape control in gold nanoparticle synthesis. Chem. Soc. Rev. 2008, 37, 1783-1791. [CrossRef] [PubMed]

6. Zhang, Y.; Chu, W.; Foroushani, A.D.; Wang, H.; Li, D.; Liu, J.; Barrow, C.J.; Wang, X.; Yang, W. New gold nanostructures for sensor applications: A review. Materials 2014, 7, 5169-5201. [CrossRef] [PubMed]

7. Salunke, B.K.; Sathiyamoorthi, E.; Tran, T.K.; Kim, B.S. Phyto-synthesized silver nanoparticles for biological applications. Korean J. Chem. Eng. 2017, 34, 943-951. [CrossRef]

8. $\quad$ Brust, M.; Walker, M.; Bethell, D.; Schiffrin, D.J.; Whyman, R. Synthesis of thiol-derivatised gold nanoparticles in a two-phase liquid-liquid system. J. Chem. Soc. Chem. Commun. 1994, 0, 801-802. [CrossRef]

9. Kim, S.; Jang, Y.; Yoon, K.Y.; Park, J. Surface engineered gold nanoparticles through highly stable metal-surfactant complexes. J. Colloid Interface Sci. 2016, 464, 110-116. [CrossRef] [PubMed]

10. Kim, I.; Lee, S.-H.; Lim, B.; Park, B.J.; Bhang, S.H.; Yu, T. Aqueous-phase synthesis of metal nanoparticles using phosphates as stabilizers. Korean J. Chem. Eng. 2017, 34, 231-233. [CrossRef]

11. Nikoobakht, B.; El-Sayed, M.A. Preparation and growth mechanism of gold nanorods (NRs) using seed-mediated growth method. Chem. Mater. 2003, 15, 1957-1962. [CrossRef]

12. Murphy, C.J.; Jana, N.R. Controlling the aspect ratio of inorganic nanorods and nanowires. Adv. Mater. 2002, 14, 80-82. [CrossRef]

13. Jana, N.R.; Gearheart, L.; Murphy, C.J. Seed-mediated growth approach for shape-controlled synthesis of spheroidal and rod-like gold nanoparticles using a surfactant template. Adv. Mater. 2001, 13, 1389-1393. [CrossRef]

14. Kim, F.; Song, J.H.; Yang, P. Photochemical synthesis of gold nanorods. J. Am. Chem. Soc. 2002, 124, 14316-14317. [CrossRef] [PubMed]

15. Pérez-Juste, J.; Pastoriza-Santos, I.; Liz-Marzán, L.M.; Mulvaney, P. Gold nanorods: Synthesis, characterization and applications. Coord. Chem. Rev. 2005, 249, 1870-1901. [CrossRef]

16. Chang, H.-H.; Murphy, C.J. Mini gold nanorods with tunable plasmonic peaks beyond $1000 \mathrm{~nm}$. Chem. Mater. 2018, 30, 1427-1435. [CrossRef]

17. Zhang, L.; Xia, K.; Lu, Z.; Li, G.; Chen, J.; Deng, Y.; Li, S.; Zhou, F.; He, N. Efficient and facile synthesis of gold nanorods with finely tunable plasmonic peaks from visible to near-IR range. Chem. Mater. 2014, 26, 1794-1798. [CrossRef]

18. Zhang, Q.; Zhou, Y.; Villarreal, E.; Lin, Y.; Zou, S.; Wang, H. Faceted gold nanorods: Nanocuboids, convex nanocuboids, and concave nanocuboids. Nano Lett. 2015, 15, 4161-4169. [CrossRef] [PubMed]

19. Wang, Y.N.; Wei, W.T.; Yang, C.W.; Huang, M.H. Seed-mediated growth of ultralong gold nanorods and nanowires with a wide range of length tunability. Langmuir 2013, 29, 10491-10497. [CrossRef] [PubMed]

20. Lu, X.; Yavuz, M.S.; Tuan, H.Y.; Korgel, B.A.; Xia, Y. Ultrathin gold nanowires can be obtained by reducing polymeric strands of oleylamine-aucl complexes formed via aurophilic interaction. J. Am. Chem. Soc. 2008, 130, 8900-8901. [CrossRef] [PubMed]

21. Pong, B.-K.; Elim, H.I.; Chong, J.-X.; Ji, W.; Trout, B.L.; Lee, J.-Y. New insights on the nanoparticle growth mechanism in the citrate reduction of gold(III) salt: Formation of the Au nanowire intermediate and its nonlinear optical properties. J. Phys. Chem. C 2007, 111, 6281-6287. [CrossRef]

22. Pei, L.; Mori, K.; Adachi, M. Formation process of two-dimensional networked gold nanowires by citrate reduction of $\mathrm{AuCl}^{4-}$ and the shape stabilization. Langmuir 2004, 20, 7837-7843. [CrossRef] [PubMed]

23. Navaladian, S.; Janet, C.M.; Viswanathan, B.; Varadarajan, T.K.; Viswanath, R.P. A facile room-temperature synthesis of gold nanowires by oxalate reduction method. J. Phys. Chem. C 2007, 111, 14150-14156. [CrossRef]

24. Huo, Z.; Tsung, C.K.; Huang, W.; Zhang, X.; Yang, P. Sub-two nanometer single crystal Au nanowires. Nano Lett. 2008, 8, 2041-2044. [CrossRef] [PubMed]

25. Zhu, C.; Peng, H.C.; Zeng, J.; Liu, J.; Gu, Z.; Xia, Y. Facile synthesis of gold wavy nanowires and investigation of their growth mechanism. J. Am. Chem. Soc. 2012, 134, 20234-20237. [CrossRef] [PubMed]

26. Chirea, M.; Freitas, A.; Vasile, B.S.; Ghitulica, C.; Pereira, C.M.; Silva, F. Gold nanowire networks: Synthesis, characterization, and catalytic activity. Langmuir 2011, 27, 3906-3913. [CrossRef] [PubMed] 
27. Seo, D.; Park, J.C.; Song, H. Polyhedral gold nanocrystals with O h symmetry: From octahedra to cubes. J. Am. Chem. Soc. 2006, 128, 14863-14870. [CrossRef] [PubMed]

28. Seo, D.; Yoo, C.I.; Park, J.C.; Park, S.M.; Ryu, S.; Song, H. Directed surface overgrowth and morphology control of polyhedral gold nanocrystals. Angew. Chem. Int. Ed. 2008, 47, 763-767. [CrossRef] [PubMed]

29. Heo, J.; Kim, D.S.; Kim, Z.H.; Lee, Y.W.; Kim, D.; Kim, M.; Kwon, K.; Park, H.J.; Yun, W.S.; Han, S.W. Controlled synthesis and characterization of the enhanced local field of octahedral Au nanocrystals. Chem. Commun. 2008, 0, 6120-6122. [CrossRef] [PubMed]

30. Sun, Y.; Xia, Y. Shape-controlled synthesis of gold and silver nanoparticles. Science 2002, 298, $2176-2179$. [CrossRef] [PubMed]

31. Sau, T.K.; Murphy, C.J. Room temperature, high-yield synthesis of multiple shapes of gold nanoparticles in aqueous solution. J. Am. Chem. Soc. 2004, 126, 8648-8649. [CrossRef] [PubMed]

32. Lee, J.H.; Gibson, K.J.; Chen, G.; Weizmann, Y. Bipyramid-templated synthesis of monodisperse anisotropic gold nanocrystals. Nat. Commun. 2015, 6, 7571. [CrossRef] [PubMed]

33. Ah, C.S.; Yun, Y.J.; Park, H.J.; Kim, W.-J.; Ha, D.H.; Yun, W.S. Size-controlled synthesis of machinable single crystalline gold nanoplates. Chem. Mater. 2005, 17, 5558-5561. [CrossRef]

34. Xin, W.; Severino, J.; De Rosa, I.M.; Yu, D.; McKay, J.; Ye, P.; Yin, X.; Yang, J.M.; Carlson, L.; Kodambaka, S. One-step synthesis of tunable-size gold nanoplates on graphene multilayers. Nano Lett. 2018, 18, 1875-1881. [CrossRef] [PubMed]

35. Huang, Y.; Ferhan, A.R.; Gao, Y.; Dandapat, A.; Kim, D.H. High-yield synthesis of triangular gold nanoplates with improved shape uniformity, tunable edge length and thickness. Nanoscale 2014, 6, 6496-6500. [CrossRef] [PubMed]

36. Oldenburg, S.J.; Averitt, R.D.; Westcott, S.L.; Halas, N.J. Nanoengineering of optical resonances. Chem. Phys. Lett. 1998, 288, 243-247. [CrossRef]

37. Graf, C.; van Blaaderen, A. Metallodielectric colloidal core-shell particles for photonic applications. Langmuir 2002, 18, 524-534. [CrossRef]

38. Gao, Y.; Gu, J.; Li, L.; Zhao, W.; Li, Y. Synthesis of gold nanoshells through improved seed-mediated growth approach: Brust-like, in situ seed formation. Langmuir 2016, 32, 2251-2258. [CrossRef] [PubMed]

39. Wu, H.-L.; Chen, C.-H.; Huang, M.H. Seed-mediated synthesis of branched gold nanocrystals derived from the side growth of pentagonal bipyramids and the formation of gold nanostars. Chem. Mater. 2009, 21, 110-114. [CrossRef]

40. Xie, J.; Lee, J.Y.; Wang, D.I.C. Seedless, surfactantless, high-yield synthesis of branched gold nanocrystals in hepes buffer solution. Chem. Mater. 2007, 19, 2823-2830. [CrossRef]

41. Li, Z.; Li, W.; Camargo, P.H.; Xia, Y. Facile synthesis of branched Au nanostructures by templating against a self-destructive lattice of magnetic Fe nanoparticles. Angew. Chem. Int. Ed. 2008, 47, 9653-9656. [CrossRef] [PubMed]

42. Kuo, C.H.; Huang, M.H. Synthesis of branched gold nanocrystals by a seeding growth approach. Langmuir 2005, 21, 2012-2016. [CrossRef] [PubMed]

43. Wu, H.Y.; Liu, M.; Huang, M.H. Direct synthesis of branched gold nanocrystals and their transformation into spherical nanoparticles. J. Phys. Chem. B 2006, 110, 19291-19294. [CrossRef] [PubMed]

44. Chen, S.; Wang, Z.L.; Ballato, J.; Foulger, S.H.; Carroll, D.L. Monopod, bipod, tripod, and tetrapod gold nanocrystals. J. Am. Chem. Soc. 2003, 125, 16186-16187. [CrossRef] [PubMed]

45. Gao, X.; Xing, G.; Chu, W.; Liang, X.; Zhao, Y.; Jing, L.; Yuan, H.; Cui, Y.; Dong, J. The growth of complex nanostructures: Synergism of dipolar force and stacking-defects in anisotropic self-assembly. Adv. Mater. 2008, 20, 1794-1798. [CrossRef]

46. Liao, H.G.; Jiang, Y.X.; Zhou, Z.Y.; Chen, S.P.; Sun, S.G. Shape-controlled synthesis of gold nanoparticles in deep eutectic solvents for studies of structure-functionality relationships in electrocatalysis. Angew. Chem. Int. Ed. 2008, 47, 9100-9103. [CrossRef] [PubMed]

47. Mohanty, A.; Garg, N.; Jin, R. A universal approach to the synthesis of noble metal nanodendrites and their catalytic properties. Angew. Chem. Int. Ed. 2010, 49, 4962-4966. [CrossRef] [PubMed]

48. Abalde-Cela, S.; Taladriz-Blanco, P.; de Oliveira, M.G.; Abell, C. Droplet microfluidics for the highly controlled synthesis of branched gold nanoparticles. Sci. Rep. 2018, 8, 2440. [CrossRef] [PubMed] 
49. Sajitha, M.; Vindhyasarumi, A.; Gopi, A.; Yoosaf, K. Shape controlled synthesis of multi-branched gold nanocrystals through a facile one-pot bifunctional biomolecular approach. RSC Adv. 2015, 5, 98318-98324. [CrossRef]

50. Nehl, C.L.; Hafner, J.H. Shape-dependent plasmon resonances of gold nanoparticles. J. Mater. Chem. 2008, 18, 2415-2419. [CrossRef]

51. Jain, P.K.; Huang, X.; El-Sayed, I.H.; El-Sayed, M.A. Noble metals on the nanoscale: Optical and photothermal properties and some applications in imaging, sensing, biology, and medicine. Acc. Chem. Res. 2008, 41, 1578-1586. [CrossRef] [PubMed]

52. Myroshnychenko, V.; Rodriguez-Fernandez, J.; Pastoriza-Santos, I.; Funston, A.M.; Novo, C.; Mulvaney, P.; Liz-Marzan, L.M.; Garcia de Abajo, F.J. Modelling the optical response of gold nanoparticles. Chem. Soc. Rev. 2008, 37, 1792-1805. [CrossRef] [PubMed]

53. Wang, A.X.; Kong, X. Review of recent progress of plasmonic materials and nano-structures for surface-enhanced raman scattering. Materials 2015, 8, 3024-3052. [CrossRef] [PubMed]

54. Dreaden, E.C.; Mackey, M.A.; Huang, X.; Kang, B.; El-Sayed, M.A. Beating cancer in multiple ways using nanogold. Chem. Soc. Rev. 2011, 40, 3391-3404. [CrossRef] [PubMed]

55. Giljohann, D.A.; Seferos, D.S.; Daniel, W.L.; Massich, M.D.; Patel, P.C.; Mirkin, C.A. Gold nanoparticles for biology and medicine. Angew. Chem. Int. Ed. 2010, 49, 3280-3294. [CrossRef] [PubMed]

56. Lal, S.; Clare, S.E.; Halas, N.J. Nanoshell-enabled photothermal cancer therapy: Impending clinical impact. Acc. Chem. Res. 2008, 41, 1842-1851. [CrossRef] [PubMed]

57. Li, N.; Zhao, P.; Astruc, D. Anisotropic gold nanoparticles: Synthesis, properties, applications, and toxicity. Angew. Chem. Int. Ed. 2014, 53, 1756-1789. [CrossRef] [PubMed]

58. Park, H.; Whang, K.; Shin, Y.; Lee, J.; Kang, T. Synthesis of colloidal plasmonic microspheres via spontaneous formation and three-dimensional assembly of metal nanoparticles. Korean J. Chem. Eng. 2017, 34, 2086-2091. [CrossRef]

59. Kim, J.; Park, S.; Lee, J.E.; Jin, S.M.; Lee, J.H.; Lee, I.S.; Yang, I.; Kim, J.S.; Kim, S.K.; Cho, M.H.; et al. Designed fabrication of multifunctional magnetic gold nanoshells and their application to magnetic resonance imaging and photothermal therapy. Angew. Chem. Int. Ed. 2006, 45, 7754-7758. [CrossRef] [PubMed]

60. Huang, X.; Neretina, S.; El-Sayed, M.A. Gold nanorods: From synthesis and properties to biological and biomedical applications. Adv. Mater. 2009, 21, 4880-4910. [CrossRef] [PubMed]

61. Park, H.; Yang, J.; Lee, J.; Haam, S.; Choi, I.H.; Yoo, K.H. Multifunctional nanoparticles for combined doxorubicin and photothermal treatments. ACS Nano 2009, 3, 2919-2926. [CrossRef] [PubMed]

62. Nam, J.; Won, N.; Jin, H.; Chung, H.; Kim, S. Ph-induced aggregation of gold nanoparticles for photothermal cancer therapy. J. Am. Chem. Soc. 2009, 131, 13639-13645. [CrossRef] [PubMed]

63. Au, L.; Zheng, D.; Zhou, F.; Li, Z.Y.; Li, X.; Xia, Y. A quantitative study on the photothermal effect of immuno gold nanocages targeted to breast cancer cells. ACS Nano 2008, 2, 1645-1652. [CrossRef] [PubMed]

64. Yang, J.; Lee, J.; Kang, J.; Oh, S.J.; Ko, H.J.; Son, J.H.; Lee, K.; Suh, J.S.; Huh, Y.M.; Haam, S. Smart drug-loaded polymer gold nanoshells for systemic and localized therapy of human epithelial cancer. Adv. Mater. 2009, 21, 4339-4342. [CrossRef] [PubMed]

65. Li, J.L.; Day, D.; Gu, M. Ultra-low energy threshold for cancer photothermal therapy using transferrin-conjugated gold nanorods. Adv. Mater. 2008, 20, 3866-3871. [CrossRef]

66. Hu, K.W.; Liu, T.M.; Chung, K.Y.; Huang, K.S.; Hsieh, C.T.; Sun, C.K.; Yeh, C.S. Efficient near-IR hyperthermia and intense nonlinear optical imaging contrast on the gold nanorod-in-shell nanostructures. J. Am. Chem. Soc. 2009, 131, 14186-14187. [CrossRef] [PubMed]

67. Qiu, P.; Yang, M.; Qu, X.; Huai, Y.; Zhu, Y.; Mao, C. Tuning photothermal properties of gold nanodendrites for in vivo cancer therapy within a wide near infrared range by simply controlling their degree of branching. Biomaterials 2016, 104, 138-144. [CrossRef] [PubMed]

68. Fazal, S.; Jayasree, A.; Sasidharan, S.; Koyakutty, M.; Nair, S.V.; Menon, D. Green synthesis of anisotropic gold nanoparticles for photothermal therapy of cancer. ACS Appl. Mater. Interfaces 2014, 6, 8080-8089. [CrossRef] [PubMed]

69. Zhang, Q.; Wang, L.; Jiang, Y.; Gao, W.; Wang, Y.; Yang, X.; Yang, X.; Liu, Z. Gold nanorods with silica shell and pamam dendrimers for efficient photothermal therapy and low toxic codelivery of anticancer drug and sirna. Adv. Mater. Interfaces 2017, 4, 1701166. [CrossRef] 
70. Mocan, L.; Matea, C.; Tabaran, F.A.; Mosteanu, O.; Pop, T.; Puia, C.; Agoston-Coldea, L.; Gonciar, D.; Kalman, E.; Zaharie, G.; et al. Selective in vitro photothermal nano-therapy of mrsa infections mediated by igg conjugated gold nanoparticles. Sci. Rep. 2016, 6, 39466. [CrossRef] [PubMed]

71. Guo, R.; Zhang, L.; Zhu, Z.; Jiang, X. Direct facile approach to the fabrication of chitosan-gold hybrid nanospheres. Langmuir 2008, 24, 3459-3464. [CrossRef] [PubMed]

72. Dozol, H.; Mériguet, G.; Ancian, B.; Cabuil, V.; Xu, H.; Wang, D.; Abou-Hassan, A. On the synthesis of Au nanoparticles using edta as a reducing agent. J. Phys. Chem. C 2013, 117, 20958-20966. [CrossRef]

73. Bonggotgetsakul, Y.Y.N.; Cattrall, R.W.; Kolev, S.D. The preparation of a gold nanoparticle monolayer on the surface of a polymer inclusion membrane using EDTA as the reducing agent. J. Membr. Sci. 2011, 379, 322-329. [CrossRef]

74. Lim, T.H.; McCarthy, D.; Hendy, S.C.; Stevens, K.J.; Brown, S.A.; Tilley, R.D. Real-time tem and kinetic monte carlo studies of the coalescence of decahedral gold nanoparticles. ACS Nano 2009, 3, 3809-3813. [CrossRef] [PubMed]

75. Ji, X.; Song, X.; Li, J.; Bai, Y.; Yang, W.; Peng, X. Size control of gold nanocrystals in citrate reduction: The third role of citrate. J. Am. Chem. Soc. 2007, 129, 13939-13948. [CrossRef] [PubMed]

76. Goia, D.; Matijević, E. Tailoring the particle size of monodispersed colloidal gold. Colloids Surf. A 1999, 146, 139-152. [CrossRef]

77. Weissleder, R. A clearer vision for in vivo imaging. Nat. Biotechnol. 2001, 19, 316-317. [CrossRef] [PubMed]

78. West, J.L.; Halas, N.J. Engineered nanomaterials for biophotonics applications: Improving sensing, imaging, and therapeutics. Annu. Rev. Biomed. Eng. 2003, 5, 285-292. [CrossRef] [PubMed]

79. Lee, J.W.; Jung, H.; Cho, H.H.; Lee, J.H.; Nam, Y. Gold nanostar-mediated neural activity control using plasmonic photothermal effects. Biomaterials 2018, 153, 59-69. [CrossRef] [PubMed]

(C) 2018 by the authors. Licensee MDPI, Basel, Switzerland. This article is an open access article distributed under the terms and conditions of the Creative Commons Attribution (CC BY) license (http://creativecommons.org/licenses/by/4.0/). 